\title{
CLASSIFYING THE SENSITIVE TYPE OF PATIENTS WITH A WEB BASED UNIT IN INFORMATION SYSTEMS FOR DOCTORS PRACTICING CLINICAL HOMEOPATHY
}

\author{
Zhivko Peychev, ${ }^{1}$ Antonia Yaneva, ${ }^{2}$ Sava Petrov, ${ }^{3}$ Stela Peycheva ${ }^{4}$
}

\begin{abstract}
In pathogenic experimentation in homeopathy on healthy volunteers, some individuals develop stronger reactions than others, i.e. they show more symptoms of the same biologically active substance. They are defined as sensitive type (ST) individuals. The aim of this work is to create a web-based module for determining ST patients in the homeopathic information system. Material and methods: We carried out an analysis of test questions relating to the definition of ST patients from a specialized homeopathy manual (Horvilleur, 2003). For the development of a web-based GUI, we used Oracle APEX. Results: For the implementation of the software module of ST and the disclosure of its features an electronic questionnaire was developed, containing 533 test questions. Processing the responses from the test allows the programming module to indicate one of 20 medications for ST patients in a specific clinical situation. Conclusion: The module for determining ST patients helps the doctor practicing clinical homeopathy to significantly shorten the time for prescribing the medicament for the terrain treatment in primary care.
\end{abstract}

JEL Classification Numbers: I100; DOI: http://dx.doi.org/10.12955/cbup.v5.1060

UDC Classification: 614.2

Keywords: sensitive type, clinical homeopathy, information systems.

\section{Introduction}

A homeopathic medical history contains information about the current, past and atopic diseases of the patient, of its behavioural effects, morphological signs, disease trends, modalities and related features that allow homeopathic doctors to detect a drug, i.e. most similar (Balzarini et al., 2000; Clausen et al., 2010; Siqueira, et al., 2016).

In modern society, web-technologies are becoming increasingly important (Clausen et al., 2014; Liberati et al., 2015; Murugesan et al., 2016; Teixeira, 2013). Currently, their effective use has become a critical success factor. Their use in homeopathic medicine helps at a great extent the specialists in search of a personal drug (P-drug) for a particular patient. The idea of developing an online poll to determine the sensitive type (ST) patients in the information system arose from the need to reduce the time to perform this process. In creating the survey was used the competence of experts in the field of homeopathy with many years of practical experience and poll issues of the specialized family guide to homeopathy (Horvilleur, 2003). The present work presents a web-based test to determine the ST patients introduced in the information system.

\section{Aim}

The purpose of this work is to create a web-based test in the homeopathic information system determining ST patients. Allowing for the minimization of errors in processing the results, as well as the time taken to calculate them.

\section{Material and methods}

Establishing the program module is implemented in two stages: first - analyzing data from a family guide to homeopathy (Horvilleur, 2003) and second - developing an online questionnaire by Oracle APEX, followed by creating an algorithm for finding the drug in accordance with these data.

\section{Results}

For the software implementation of the ST module and the disclosure of its features we developed an electronic poll containing 533 test questions that the patient should answer with "Yes" or "No." To introduce the poll, we prepared data for import into a table format using MS Excel.

\footnotetext{
${ }^{1}$ Medical University - Plovdiv, Bulgaria, Faculty of Public Health, zhpeychev@ meduniversity-plovdiv.bg

${ }^{2}$ Medical University - Plovdiv, Bulgaria,ayaneva@ meduniversity-plovdiv.bg

${ }^{3}$ Medical University - Plovdiv, Bulgaria, Faculty of Medicine Section Endocrinology and metabolic diseases, spetrov@meduniversity-plovdiv.bg

${ }^{4}$ Medical University - Plovdiv, Bulgaria, Faculty of Dental Medicine, angelova_stela@abv.bg
} 
The implementation of the electronic poll put into the system follows the following algorithm (Figure $1)^{5}$ :

\begin{tabular}{l} 
Figure 1: Software algorithm to determine the ST patients \\
$\begin{array}{c}\text { Answer "Yes" - Printing in } \\
\text { List } \mathrm{X} \text { and going to the } \\
\text { next question. } \\
\text { the next question }\end{array}$ \\
$\begin{array}{c}\text { Processing values for } \\
\text { displaying medication } \\
\text { with the greatest number } \\
\text { of matches in the list }\end{array}$ \\
\hline $\begin{array}{c}\text { Source: Author } \\
\text { Anstions }\end{array}$
\end{tabular}

The answer of the questions provides information on specific morphological features, individual behaviors and typical disease trends of the ST patient. The system displays the result on the basis of which the doctor prescribes the medicine for the ST, i.e. prescribing appropriate terrain treatment.

As a result of the established algorithm for ST patients, we practically tested the module created by a clinical case: A 51-year-old woman in perimenopause reports an irregular monthly cycle over the past year. Frequent fits of warm waves and blood pressure fluctuations, sleep disturbances, confusion and intolerance to the surrounding people. Refuses to carry out hormonal replacement therapy for climacteric Prefers to use homeopathy as a safe therapeutic method for warm waves and climax.

In the specific clinical case, the patient responds positively to 8 of the questions. The data are presented in Table 1:

Table 1: Data from a test for a sensitive patient
\begin{tabular}{|c|c|c|}
\hline № & Question & Answer \\
\hline 6 & $\begin{array}{c}\text { I often get bruises without bumping into edges } \\
\text { and furniture }\end{array}$ & Yes \\
\hline 15 & I'm in menopause, or almost on the verge of it. & Yes \\
\hline 46 & $\begin{array}{c}\text { I often feel bad with a belt fastened when } \\
\text { driving. }\end{array}$ & Yes \\
\hline 79 & I am a woman who is often sweating suddenly & Yes \\
\hline 93 & I am a woman who is often dreaming of death & Yes \\
\hline 121 & I am often hot & Yes \\
\hline 127 & I am a woman who can hardly tolerate aging & Yes \\
\hline 137 & I often dream of snakes & Yes \\
\hline
\end{tabular}

Source: Author

Test data for a sensitive patient type are reflected in the web based information system, and as a result, the system outputs the homeopathic drug data presented in Figure 2:

\footnotetext{
${ }^{5}$ Software algorithm to determine the sensitive type patients
} 


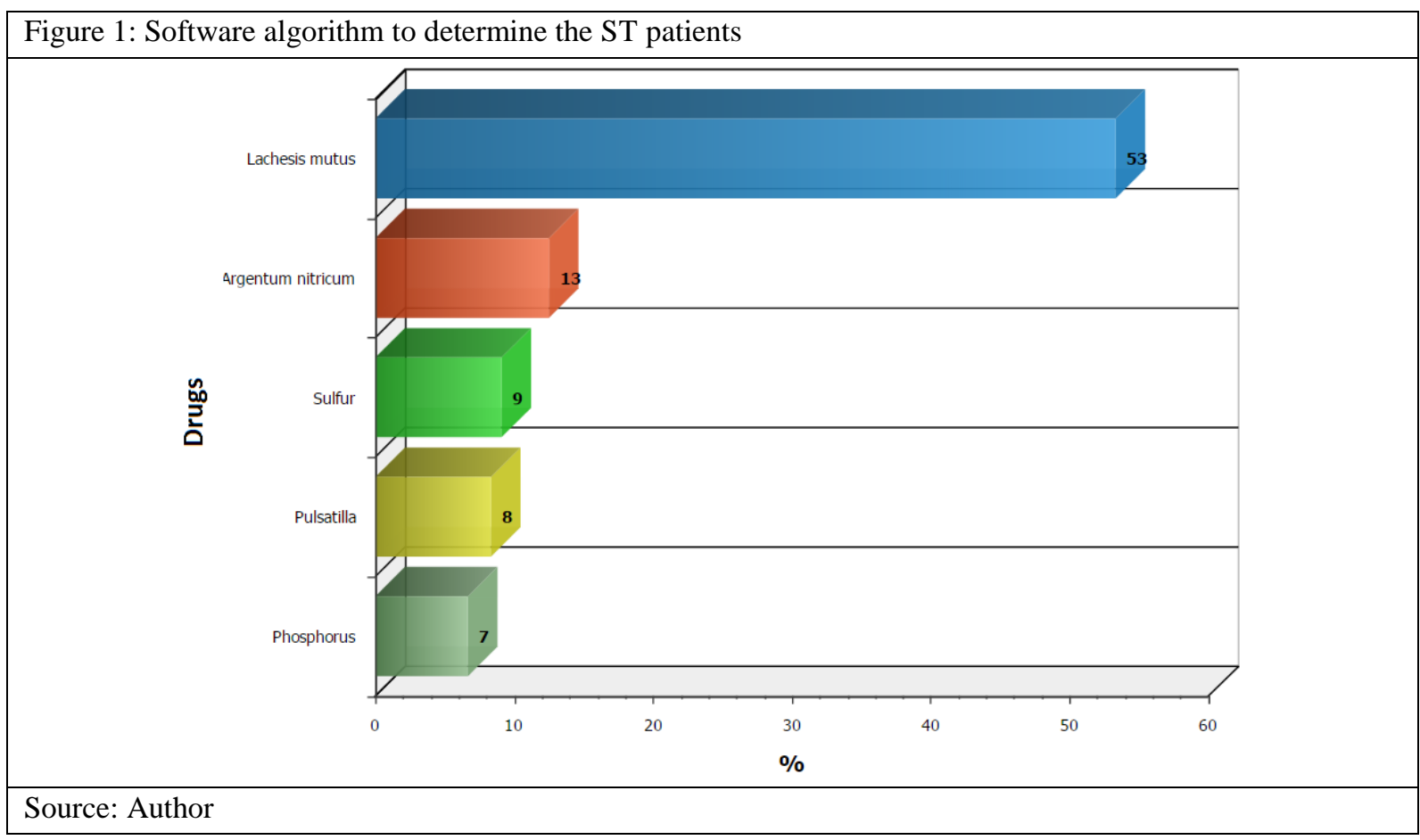

As a leading drug the system lists Lachesis mutus, because the identification of a patient of Sensitive Type is performed in three sets of criteria. They are morphological features; behavioral reactions and disease trends.

The peculiarities of the morphological feature are: female patients, in menopause with a characteristic marbled face, violet red nose, dark red or violet lips.

Analysing the behavioral responses we found female patients prone to jealousy, mistrust, alternating volubility and depression again. Disease trends: during climacterium, capillary brittleness and mar; painful hemorrhoids are relieved by bleeding. Different phobias occur, such as fear of death, fear of falling asleep, fear of poisoning, pathological jealousy and sighs; intolerance to everything that tightens. Secondly, the system specifies Argentum nitricum (13\%), and Sulfur in third place, based on a history of hyperemia and diseases of the cardiovascular system, the locomotor system and the skin.

\section{Discussion}

ST patients to a given substance are individuals who in pathogenic experimentation exhibit more symptoms than others and in carrying out the therapy are in need of a lower dose of the drug compared to the others (Horvilleur, 2003). There are three characteristics of the ST patients: similar morphological features, similar nature, and related pathological trends. The history and clinical patient data used until now, make the right choice of the homeopathic treatment difficult and slow. We offer a computerized-testing system that speeds up the process and ensures a high degree of similarity in the choice of treatment. The benefit of an information system for determining the ST consists in the fact that the clinician is oriented quickly in the choice of drug and can predict the development of the disease process. The manifested morphological and characterological features and pathological history of the patient directly to a particular drug. Since the phenotype of the individual is the visible part of its genotype, which determines the "terrain," we can predict the disease progression and can use drug with a preventative role in disease trends of the individual. Some authors exaggerate the importance of the concept of the sensitive type. For example, Kent - the founder of classical homeopathy puts emphasis on the psychological nuances of the patient than on the real existing disease trends as a result of which a number of inconsistencies in the treatment occur (Jouanny et al., 1998).

Homeopathy is a sophisticated form of personalized medicine - treatment of a specific patient with his individual reactions to the disease factors. Each person responds to the disease in its own way depending on the immune system or their genetic predisposition to one or another disease. Therefore, every person has a kind of "terrain," within which occurs the influence of environmental and genetic heredity (Germonpre et al., 2000). 
„Terrain"is a basic concept in homeopathy, which combines data for a constitutional type, chronic way of reaction and a sensitive type. Each of these elements has its own subspecies. The constitutional type has four subtypes depending on the content of minerals in the body: carbon type, phosphorus type, fluorine type and a sulfur type. The chronic way of response is divided into: psoric, tubercular, sycotic and luetic type. About fifty prototypes of the ST are described. Three sets of criteria are used to identify the specific ST - morphological features, behavioral responses and disease trends. The ST is the basis of the so-called "homeopathic typology of personality" which is linked to a strictly defined homeopathic medicine (Bule et al., 2007). The ST is changeable and rarely remains the same during the whole lifetime of men. Virtually, pure ST does not exist, but rather there is a dominant type with features added from other types and constitutions, which from informational point of view makes their identification difficult.

\section{Conclusion}

A module for detecting the signs of a Sensitive Type of patient has been created to provide homeopathic physician with information on adequate terrain treatment in acute and chronic pathology.

The module helps the doctor practicing clinical homeopathy to significantly shorten the time for prescribing the medicament for the terrain treatment in primary care thus ensuring effective use of a Physician's resources in the diagnostic and healing process.

\section{References}

Balzarini, A., Felisi, E., Martini, A., \& De Conno, F. (2000). Efficacy of homeopathic treatment of skin reactions during radiotherapy for breast cancer: a randomised, double-blind clinical trial. 89(1), 8-12. doi:10.1054/homp.1999.0328

Bule, J., Demonso, A., \& Done, F. (2007). Thérapeutique homéopathique: Schémas \& Protocoles. CEDH France.

Clausen, J., Sian, M., Alexander, T., Lüdtke, R., \& Albrecht, H. (2014). CORE-Hom: A powerful and exhaustive database of clinical trials in homeopathy. Homeopathy, 219-223.

Clausen, J., van Wijk, R., \& Albrecht, H. (2010). Infection models in basic research on homeopathy. 99(4), 263-270.

Germonpre, M., Pinkas, M., \& Tork, M. (2000). Matiére Médicale Homéopathique.

Horvilleur, A. (2003). L Homeopathie Pour Mes Enfants. Librairie Generale Francaise.

Jouanny, J., Crapagne, J., Dance, A., \& Mason, J. (1998). Thérapeutique Homeopathique. Possibilites en pathologie aiguë. 2.

Liberati, E. G., Gallupo, L., Maraldi, M. M., Ruggiero, F., Capobussi, M., Banzi, R., . . Moja, L. (2015). Barriere e facilitatori all'implementazione dei sistemi di supporto decisionale computerizzati in ospedale: uno studio "grounded theory". Recenti in Progressi in Medicina, 106, 180-191.

Murugesan, S., Deshpande, Y., Hansen, S., \& Athula, G. (2016). Web Engineering: a New Discipline for Development of Web-Based Systems. 3-13.

Siqueira, C., Homsani, F., da Veiga, V., Lyrio,, C., Mattos, H., Passos, S. R., . . Quaresma, C. H. (2016). 105(1), 71-77.

Teixeira, M. Z. (2013). New Homeopathic Medicines' database: A project to employ conventional drugs according to the homeopathic method of treatment. European Journal of Integrative Medicine, 270-278. 